\title{
ELECTRICAL CHARACTERIZATION OF ALUMINUM (AI) THIN FILMS MEASURED BY USING FOUR- POINT PROBE METHOD
}

\author{
${ }^{1}$ G. P. Panta, ${ }^{1}$ D. P. Subedi ${ }^{*}$ \\ Department of Natural Sciences (Physics) School of Science, Kathmandu University \\ Dhulikhel, Kavre, Nepal \\ *Corresponding author: deepaksubedi2001@yahoo.com \\ Received 17 June, 2012; Revised 29 September, 2012
}

\begin{abstract}
This paper reports the results of electrical characterization of aluminum thin films. Uniform Al thin films were deposited by physical vapor deposition (PVD) technique on glass substrates. The electrical resistivity of the films as a function of film thickness was studied. These parameters have been measured by four-point probe method. The electrical resistivity was obtained by the measurement of current (in $\mathrm{mA}$ ) and voltage in (mV) through the probe. The results showed that resistivity of the film decreases linearly with the film thickness in the range of the thickness studied in this work.
\end{abstract}

Keywords: Aluminum thin films, electrical resistivity $(\rho)$, electrical conductivity $(\sigma)$, sheet resistance $\left(R_{s}\right)$, thickness of $A l$ thin films, four- probe set up

\section{INTRODUCTION}

The new tendencies of miniaturization of electrochemical components are causing a revolution in the materials field. Particularly, materials with thin films geometry deposited on thick substrates present physical properties that can be more relevant than for bulk $[1,2]$. There are several physical properties that change depending on the film thickness and kind of material. Some thin film semiconductors present electrical and optical properties that depend on the thickness of the deposited films. Metals tend to increase their electrical resistivity $(\rho)$ and sheet resistance $\left(\mathrm{R}_{\mathrm{s}}\right)$ when thickness decreases between the mean free path and certain coalescence limits. It means that the electrical conductivity $(\sigma)$ of metals thin films increase with the increase in thickness of thin films and remains almost constant at bulk state for particular metals $[3,4]$. Due to amazing results of thin films, the actual demand of micro devices used as micro-sensors to control or to measure certain physical parameters for specific applications is increasing [5]. These efforts follow two basic objectives: to increase the range of use and the capacity of the devices, as well as to reduce the device size and to increase the materials quality [6]. There are different physical properties that can be studied in a known material in order to obtain a possible new behavior [7]. In this work, a study of electrical properties of $A l$ thin films deposited by physical vapor deposition (PVD) technique on glass substrates is described. The importance and role of the metallic film-substrate geometry as well as the methodology used to obtain some electrical properties have been explained. The obtained results may be of great interest due to the direct application in the microelectronic industry.

\section{MATERIALS AND METHODS Experimental Set-Up and Procedures}

The Hind High Vacuum box coater model BC 300 was used to deposit $A l$ films on glass substrates. Aluminum thin films with different thickness ranging from $0.1483 \mu \mathrm{m} 0.225 \mu \mathrm{m}$ were deposited in chamber with pressure approximately $2 \times 10^{-6} \mathrm{mbar}$. Tungsten coil was used to evaporate the high purity $\mathrm{Al}$ metal. Glass substrates were cleaned first with distilled water then by ethanol in ultrasonic bath and finally with the low pressure glow discharge. The 
thickness of the films were controlled during deposition by a quartz crystal and thickness measured by DTM thickness monitor model 101.

The deposition LT (Low-Tension) current for all thickness of thin films was taken about 4050A. The deposition rate in all experiments was about $10 \mathrm{~A} / \mathrm{sec}$ and films thickness ranged between $0.1483 \mu \mathrm{m}$ and $0.225 \mu \mathrm{m}$. The rotary pump reduced pressure from atmospheric to 0.001 mbar then diffusion pump was started for the further reduction in pressure. Then diffusion pump decreased the pressure from 0.001 mbar to $2 \times 10^{-6}$ mbar. The desired thickness of the film was obtained deposited on glass substrates within one minute. Finally, all deposited samples have been taken for resistive properties measurement by using four probe method.

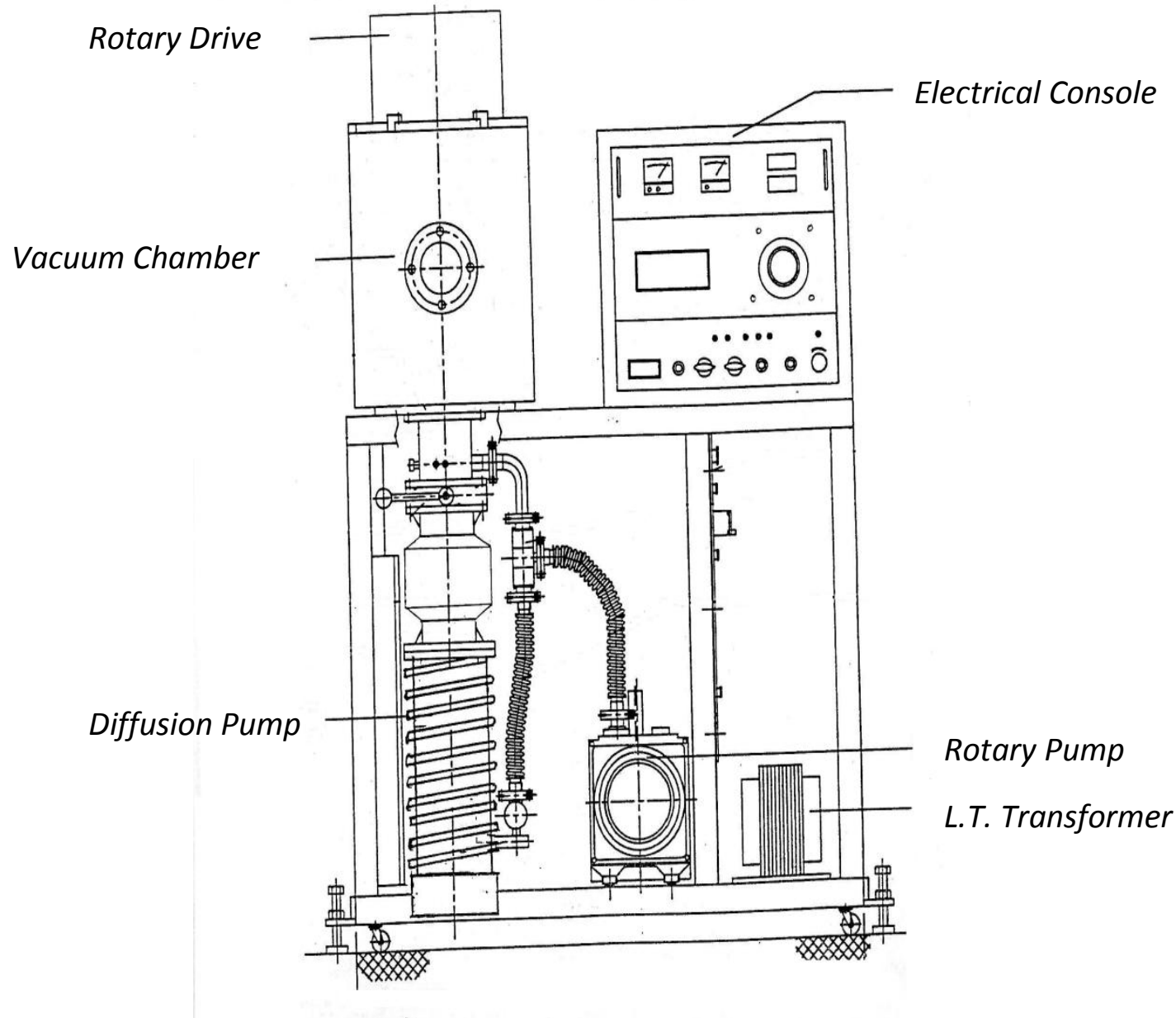

Fig. 1 Hind High Vacuum Box Coater Model BC- 300 for deposition of Al thin films on glass substrates 


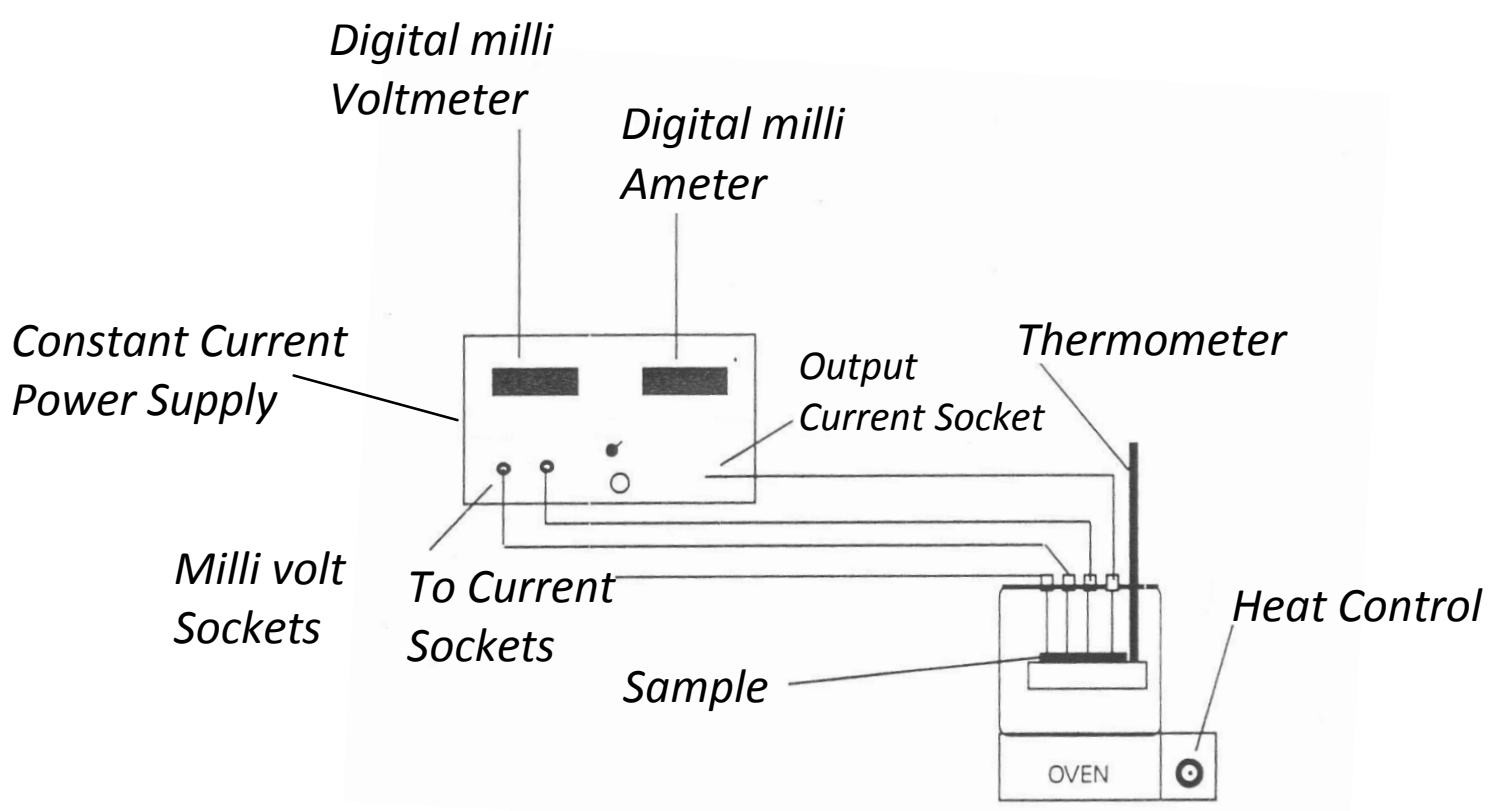

Fig.2 Schematic diagram of the four-point probe used for the measurement of electrical resistivity of $\mathrm{Al}$ thin films.

\section{THEORY}

The four-point probes are placed collinearly with equal spacing between them on the sample. The current is passed through the two outer probes and the potential is measured between the two inner probes. The errors due to electrical contacts are absent because the current and voltage leads are separate. This is a widely used technique to measure the electrical resistivity by superficial contact. This technique is mainly used in the semiconductor industry, research and manufacturing field.

In the first experiment, the resistivity of $G e$ semiconductor crystal is given by Eq. (1).

$$
\rho=(\mathrm{V} / \mathrm{I}) \times 2 \pi \mathrm{s}
$$

Where $\mathrm{V}$ is the voltage in $\mathrm{mV}$, $\mathrm{I}$ is the current in $m A$ and $\mathrm{s}$ is the spacing between two point electrode. Here, $\mathrm{s}=1.5 \mathrm{~mm}$

But in case of thin metallic films, the electrical resistivity $(\rho)$ of the film, whose length is much longer than its thickness $d$ can be obtained by formula as expressed in (2) [1,2].

$$
\begin{aligned}
& \rho=(\pi / \ln 2)(\mathrm{V} / \mathrm{I}) \times \mathrm{d} \\
& \rho \approx 4.532(\mathrm{~V} / \mathrm{I}) \times \mathrm{d}
\end{aligned}
$$

Where $\mathrm{V}$ is the drop potential measured among the internal electrodes and $\mathrm{I}$ is the current in $\mathrm{mA}$ and $\mathrm{d}=$ thickness of thin film. The electrical conductivity of the films can be obtained by

$$
\sigma=1 / \rho
$$

Knowing the values of $\rho$ and thickness of thin films, the sheet resistance can be determined according to Equation (4) [1,2]

$$
R_{s}=\rho / d
$$




\section{RESULTS AND DISCUSSIONS}

The variation of electrical resistivity with films thickness is shown in Figure- 3. It shows that with increase of thickness of $A l$ thin films, the resistivity decreases. Fig. 4 shows the plot of conductivity as a function of film thickness. Similarly, sheet resistance decreases when films thickness increases as shown in Fig. 5. These values obtained for the thin films differ from the bulk values. Thus, the electrical resistivity, conductivity and sheet resistance of aluminum thin films were measured and compared with bulk value. Table 1 shows the results of average electrical resistivity, average electrical conductivity and average sheet resistance which were determined for aluminum thin films of different thicknesses.

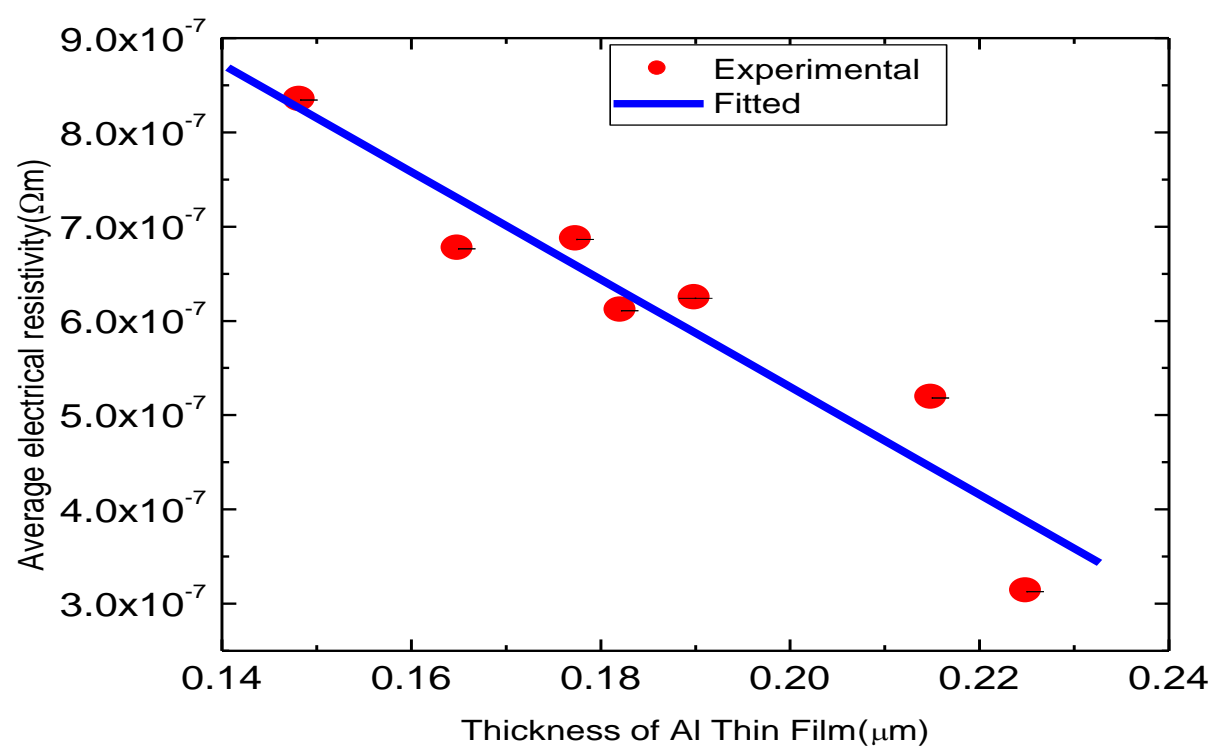

Fig 3. Variation of average electrical resistivity $(\rho)$ with thickness of Al thin films

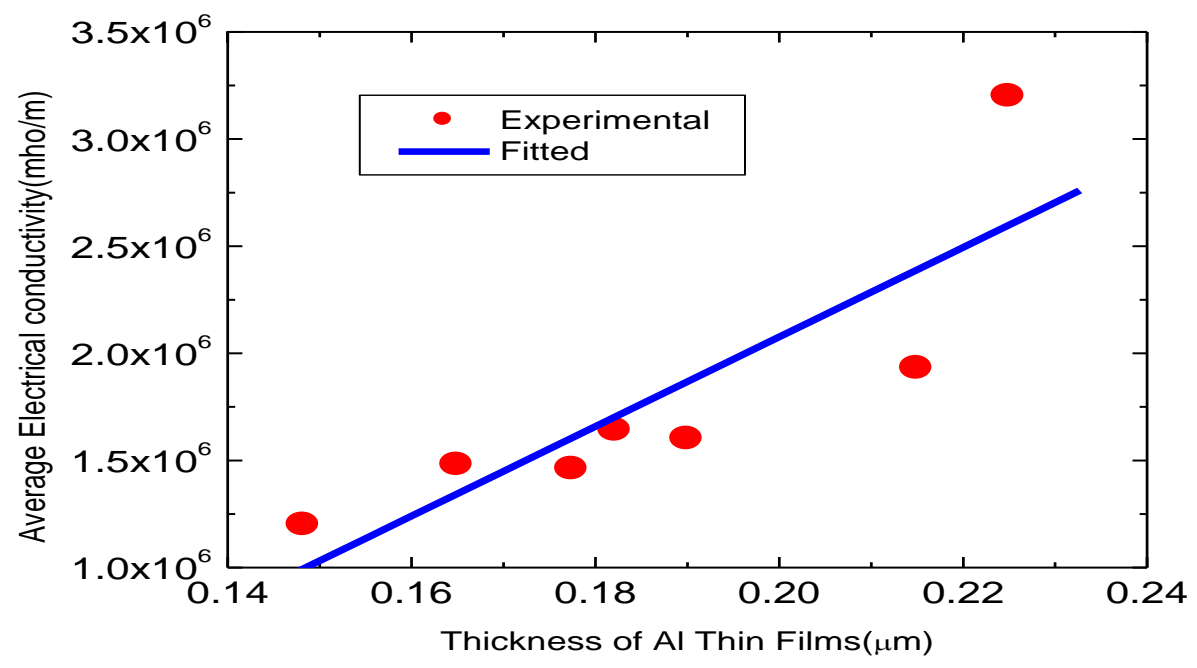

Fig 4: Variation of average electrical conductivity $(\sigma)$ with thickness of Al thin films 


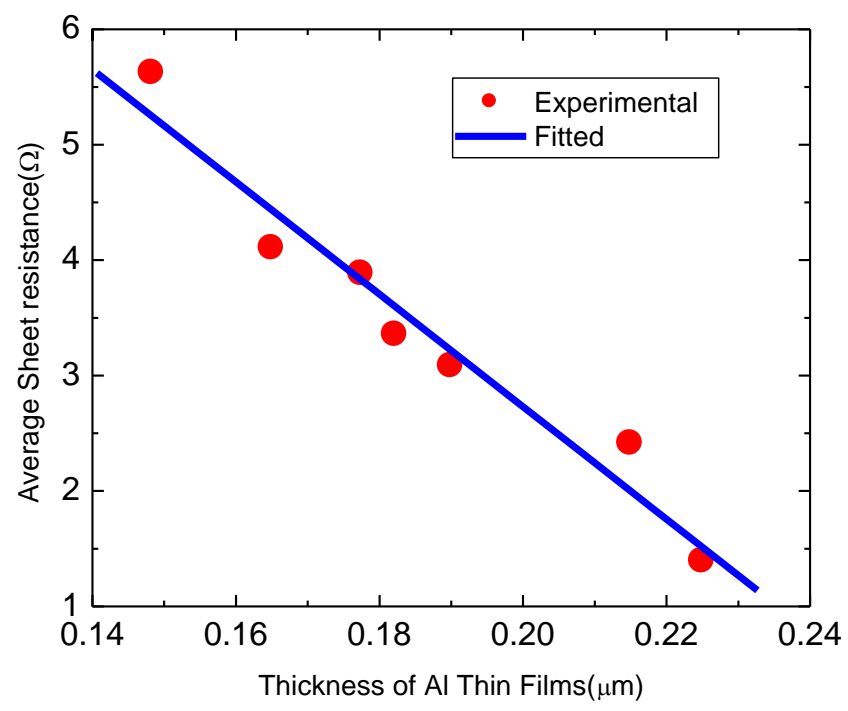

Fig 5: Variation of average sheet resistance $\left(\mathrm{R}_{\mathrm{s}}\right)$ with thickness of $\mathrm{Al}$ thin films

Table 1. Average electrical resistivity, average electrical conductivity, sheet resistance and thickness of $\mathrm{Al}$ thin films

\begin{tabular}{|c|c|c|c|c|c|}
\hline $\begin{array}{l}\text { S. } \\
\text { N. }\end{array}$ & $\begin{array}{l}\text { Al thin } \\
\text { Films } \\
\text { samples }\end{array}$ & $\begin{array}{l}\text { Thickness } \\
\text { of Al Thin } \\
\text { films } d \\
(\mu m)\end{array}$ & $\begin{array}{c}\text { Average Electrical } \\
\text { Resistivity } \rho \\
(\Omega \mathrm{m})\end{array}$ & $\begin{array}{c}\text { Average Electrical } \\
\text { Conductivity } \\
\sigma(m h o / m)\end{array}$ & $\begin{array}{l}\text { Average } \\
\text { Sheet } \\
\text { Resistance } \\
\mathrm{R}_{\mathrm{s}}(\Omega)\end{array}$ \\
\hline 1 & $\mathrm{~S}_{1}$ & 0.225 & $31.28 \times 10^{-8} \pm 4.0 \times 10^{-8}$ & $3.20 \times 10^{6} \pm 0.82 \times 10^{6}$ & $1.39 \pm 0.17$ \\
\hline 2 & $\mathrm{~S}_{2}$ & 0.1775 & $68.64 \times 10^{-8} \pm 7.35 \times 10^{-8}$ & $1.46 \times 10^{6} \pm 1.46 \times 10^{6}$ & $3.88 \pm 0.42$ \\
\hline 3 & $\mathrm{~S}_{3}$ & 0.1822 & $61.07 \times 10^{-8} \pm 13.80 \times 10^{-8}$ & $1.64 \times 10^{6} \pm 0.21 \times 10^{6}$ & $3.35 \pm 0.75$ \\
\hline 4 & $\mathrm{~S}_{4}$ & 0.1483 & $83.42 \times 10^{-8} \pm 11 \times 10^{-8}$ & $1.20 \times 10^{6} \pm 0.14 \times 10^{6}$ & $5.62 \pm 0.74$ \\
\hline 5 & $\mathrm{~S}_{5}$ & 0.1900 & $62.39 \times 10^{-8} \pm 7.02 \times 10^{-8}$ & $1.60 \times 10^{6} \pm 0.16 \times 10^{6}$ & $3.08 \pm 0.37$ \\
\hline 6 & $\mathrm{~S}_{6}$ & 0.2150 & $51.82 \times 10^{-8} \pm 11.56 \times 10^{-8}$ & $1.93 \times 10^{6} \pm 0.24 \times 10^{6}$ & $2.41 \pm 0.54$ \\
\hline 7 & $\mathrm{~S}_{7}$ & 0.1650 & $67.63 \times 10^{-8} \pm 7.66 \times 10^{-8}$ & $1.48 \times 10^{6} \pm 0.10 \times 10^{6}$ & $4.10 \pm 0.46$ \\
\hline
\end{tabular}

Unlike the properties of bulk materials, the resistivity, conductivity and sheet resistance in the thin film depends on several factors such as rate of deposition, thickness, temperature and grain boundaries between others[8]. As the thickness of the film decreases, the electron collisions with surfaces become important. Such confinement effect due to film thickness is clearly observed on $\mathrm{Al}$ thin films whose electrical resistivity values are higher than bulk. Aluminum usually presents a native oxide film $\left(\mathrm{Al}_{2} \mathrm{O}_{3}\right)$ when exposed to atmospheric pressure, which changes substantially its surface properties[8]. As can be seen in Table1, the 
measured $\rho, \sigma$ and $R_{s}$ values show variation with thickness. The analysis and behavior of the oxide layer in aluminum films require a more detailed study and will be the subject of another work.

\section{CONCLUSION}

We have studied the resistive properties of Al thin films with thickness between $0.1483 \mu \mathrm{m}$ to $0.225 \mu \mathrm{m}$ deposited on glass substrates. A methodology to characterize metallic thin films and to measure electrical properties as a function of thickness is discussed. The electrical resistivity measured on $\mathrm{Al}$ thin films is larger than those measured in bulk. The present study will be extended in future to investigate the optical and mechanical properties.

\section{REFERENCES}

[1] Chopra K L, Thin Film Phenomena MC Graw Hill Co., New York, USA, (1969).

[2] Maissel L I \& Glang R, (eds) Hand book of Thin Film technology, MC Graw Hill Co., New York, USA, (1970).

[3] Ohring M, Engineering Material Science, Academic Press, Salt Lake City, USA, (1995).

[4] Eckertov'a L, Physics of Thin Films ,Plenum Press, New York, USA, (1986)

[5] Ohring M, Materials Science of Thin Films, Academic Press, Salt Lake City, USA, (2002).

[6] Pulker H K, Coatings on Glass, Elsevier, Ave New York, USA,(1999).

[7] Oliva A I , Quintana P Ceh O, Corona J E \& Aguilar M ,Thin Solid Film, Elsevier, 353 (1999)1.

[8] Oliva A I, Aviles F\& Ceh O, Physical properties of AU and AL thin films measured by resistive heating, Surface Review and Letters, Vol.12, No.1(2005),101-106,World Scientific Publishing Company. 